\title{
Functional and self-care capacity of people with multiple sclerosis
}

\author{
Ana Railka de Souza Oliveira-Kumakura ${ }^{1}$ \\ (1D) https://orcid.org/0000-0002-7075-7987 \\ Larissa Maria Bezutti ${ }^{1}$ \\ (1) https://orcid.org/0000-0002-5304-8425 \\ Juliany Lino Gomes Silva ${ }^{1}$ \\ (1D) https://orcid.org/0000-0002-2930-103X \\ Renata Cristina Gasparino ${ }^{1}$ \\ (D) https://orcid.org/0000-0001-8729-4707
}

Universidade Estadual de Campinas, Faculdade de Enfermagem, Campinas, SP, Brazil.
Objective: describe the self-care and functionality levels of patients with multiple sclerosis and determine whether sociodemographic, clinical and functional variables interfere with self-care and/or functionality. Method: correlational, cross-sectional study with a quantitative approach performed with individuals in outpatient follow-up. We collected sociodemographic and clinical data and applied the Appraisal of Self-care Agency Scale, the Barthel index, the Lawtton and Brody Scale, and the instrument to investigate the performance in Advanced Activities of Daily Living. We performed descriptive and inferential analysis. Results: most patients were classified as "having selfcare" (82.14\%); with moderate dependence (51.19\%) for the basic activities of daily living, partial dependence for the instrumental activities of daily living (55.95\%), and more active for the advanced activities of daily living (85.71\%). Patients with longer disease duration had a higher number of disabilities and, in those with better socioeconomic and educational profile, the functionality was better. Conclusion: disease duration was strongly correlated with a higher number of disabilities and better socioeconomic and educational profiles showed to be protective factors for functionality. Care planning should consider the needs observed by the multidisciplinary team, stimulating the development of self-care, functionality and sociability.

Descriptors: Activities of Daily Living; SelfCare; Multiple Sclerosis; Human Activities; Chronic Disease; Nursing.

\section{How to cite this article}

Oliveira-Kumakura ARS, Bezutti LM, Silva JLG, Gasparino RC. Functional and self-care capacity of people with multiple sclerosis. Rev. Latino-Am. Enfermagem. 2019;27:e3183. [Access † 1 ; ] ; Available in: DOI: http://dx.doi.org/10.1590/1518-8345.3068.3183. month day year 


\section{Introduction}

Multiple sclerosis (MS) is a chronic inflammatory disease of the central nervous system (CNS), with an autoimmune, demyelinating character that leads to defects in the conduction of synapses. This results in motor and sensory deficits that can last for days or weeks and are completely or partially reversible. Thus, the evolution is characterized by attacks, acute recurrences or follows a progressive clinical course ${ }^{(1-4)}$.

The disease affects about 2.5 million people in the world, in the age group from 20 to 45 years, mostly women, with a higher prevalence in temperate regions $^{(2-3)}$. In Brazil, although the distribution is still not well known, the Southeast region has a higher prevalence, of 15 cases $/ 100,000$ habitants ${ }^{(5-6)}$. The etiology is unknown, but it is suggested that it is a multifactorial event, caused by genetic predisposition, autoimmune disease, environmental factors, emotional and/or psychological stress ${ }^{(1-4)}$.

Typically there may be numerous restrictions for the individual, initiated with uncontrollable fatigue or weakness, which may be followed by paresis or hemiparesis, spasticity, gait alteration, incoordination of movements and involuntary tremors. The most common symptoms are monocular visual loss due to optic neuritis, double vision caused by brain stem dysfunction, sensory loss because of transverse myelitis and/or ataxia due to a cerebellar lesion(1-8).

Other manifestations are cognitive dysfunction, in which there are difficulties to maintain attention, alterations in verbal fluency, decreased information processing capacity and memory problems. There may also be alterations in language (dysarthria and/or aphasia), vesical symptoms (alterations in frequency/ urgency), intestinal symptoms (constipation more often), as well as autonomic dysreflexia that can lead to cardiovascular alterations, thermal deregulation, or heat sensitivity ${ }^{(7-8)}$. Other conditions that may not be visible to healthcare professionals include anxiety, stress, depression, pain, altered sleep patterns, and sexual dysfunction ${ }^{(1-8)}$.

Considering this context, it is important to discuss the rehabilitation of individuals with MS, because it is an incapacitating disease that gradually affects the person's self-care capacity and causes functional decline, evidenced by the evaluation of basic, instrumental, and advanced activities of daily living. Such activities, if compromised, may have an impact not only on self- care, but also on quality of life, social interaction, and may contribute to the isolation of the individual ${ }^{(9-10)}$.

Self-care is defined by the World Health Organization (WHO) as "the capacity of individuals, families and communities to promote health, prevent disease, maintain health, and deal with diseases and disabilities with or without support from a health care provider"(11). Functionality, according to the International Classification of Functioning, Disability and Health (ICF), reflects the interaction between the health condition and the environmental and personal context of the individual and depends on the preservation of autonomy and independence, which are ensured by the preservation of cognition, humor, mobility, and communication ${ }^{(12)}$. This evidences that the relation between these constructs is bidirectional: functional capacity affects self-care and vice-versa.

In this context, nurses have a fundamental role in integrating the multidisciplinary team and ensuring the promotion, protection, and rehabilitation of health, focusing on the maintenance of self-care and on the functionality of these patients. However, we noticed a shortage of scientific publications, including nursing, to address this issue. Therefore, the objectives of the study were to describe the levels of self-care and functionality of patients with multiple sclerosis and to verify if sociodemographic, clinical, and functional variables interfere with self-care and/or functionality. We believe that this study may contribute to improve the care, the professionals' understanding about functionality and selfcare, and to the development of rehabilitation services.

\section{Method}

Correlational, quantitative, and cross-sectional study carried out in outpatient clinics of a public tertiary hospital in the city of Campinas, São Paulo, Brazil, from October to December 2017. We included patients regardless of disease diagnosis time, aged above 18 years, and excluded those with other neurological diseases. The sample size was calculated with the objective of evaluating the correlation between functionality and self-care by Pearson's correlation coefficient. We assumed a test power of $80 \%$, a significance level of $5 \%$, an estimate for the correlation coefficient equal to 0.30 , which can be considered a coefficient of average degree, and a correlation coefficient equal to 0.00 as null hypothesis ${ }^{(13)}$. The calculation resulted in a minimum sample of 84 patients. To perform the sample calculations we used the G*Power 3.1.9.2. software. 
An undergraduate nursing student, in the last year of the course, collected the data. She received 8-hour training, which included theoretical and practical aspects for the application of the scales, from the main researcher, advisor for the study. The other assistant researchers contributed with the analysis and interpretation of the results.

The collection instrument included sociodemographic data (age, sex, family income, city of birth, professional and civil situation) and clinical data (type of MS, medications in use, clinical manifestations) collected directly from patients through interviews. We applied the following scales translated and validated for use in Brazil: Appraisal of Self-care Agency Scale - Revised (ASA-R) (14-15), Lawton and Brody Scale (LBS)(16), and Barthel Index $(\mathrm{BI})^{(17)}$. We also used the instrument to investigate the performance of Advanced Activities of Daily Living (AADLs) $^{(18)}$.

To supplement the evaluation, we collected from the medical chart the Kurtzke Expanded Disability Status Scale (EDSS) score attributed by the neurologist during the consultation of the day. The EDSS is a medical scale that evaluates the level of disabilities clinically observed of the individual with MS. It is divided into eight functional systems (pyramidal, cerebellar, brain stem, sensory, intestine and bladder, visual, cerebral and others) and based on these indicators a score is attributed that ranges from 0 (normal) up to 10 (death by MS). Higher scores reflect a higher level of disability ${ }^{(19)}$.

The ASA-R is based on Dorothea Orem's Self-Care Deficit Theory and evaluates a human being's ability to perform the practices in the care of oneself, in the relation between the individual and the environment(20). It is a Likert-type scale with 15 items and five answer options (I totally disagree, I disagree, I do not know, I agree, and I totally agree) and presents three possible results named as: "Having capacity for self-care, Developing capacity for self-care, and Lacking capacity for self-care." The possible interval for the total measure ranges from 15 to 75 points, and higher values reflect higher self-care capacity(14-15,20).

The LBS evaluates the functional condition for instrumental activities of daily living (IADL) graded as to the degree of assistance required for each activity, namely: use telephone, shop, prepare meal, perform domestic activities, use means of transport, take medications, and manage finance ${ }^{(14)}$. The score for each item ranges from 1 to 3 and, for global interpretation, the scale was converted into three groups: equal to or lower than 7 means total dependence; from 7 to 20 corresponds to partial dependence; and equal to 21 expresses independence ${ }^{(21)}$.

The BI evaluates the basic activities of daily living (BADLs) and aims to evaluate independence (physical or verbal) in personal care, mobility, locomotion, and eliminations. It has ten items and each one is scored according to the patient's performance. The score ranges from 0 to 100: a total of 0-20 indicates total dependence; 21-60, severe dependence; 61-90, moderate dependence; 91-99, slight dependence; and 100, independence ${ }^{(17,22)}$.

To evaluate the AADLs we used the same instrument used in the longitudinal study Health, Welfare and Aging (SABE). The AADLs comprise 12 social, productive, physical and leisure activities that involve superior cognitive functions, which are: (1) contact with other people by means of letters, telephone or email; (2) visiting friends and family members at their homes; (3) care or assistance to other people (including personal care, transportation, purchases for family or friends); (4) voluntary work outside the home; (5) trip out of the city spending at least one night out; (6) participation in any regular exercise program (e.g. sports, physical exercises, walks and corporal practice groups); (7) inviting people to come to your home for meals or leisure; (8) go out with other people to public places such as restaurant or cinema; (9) conducting some manual activity, crafts or artistic activity; (10) participation in organized social activities (clubs, community or religious groups, elderly coexistence centers, bingo); (11) using computer, including the Internet; (12) driving motor vehicles ${ }^{(18)}$.

The questions for evaluating the AADLs were answered through a scale with five answer options (always, often, occasionally, rarely, and never). The answers: always, often, and occasionally were considered as performance of the activity and received value 1 . The total score ranged from 0 to 12 , being classified as "more active" those who performed five or more activities(18).

We used descriptive statistics with frequency, dispersion measures and central tendency. We applied the Shapiro-Wilk test to check the normality of the numerical data. For comparisons involving a qualitative variable with two categories and one quantitative variable, we applied the non-parametric Mann-Whitney test or the unpaired student's t-test, according to the data distribution. For comparisons involving one 
qualitative variable with more than two categories and one quantitative variable, we applied the non-parametric Kruskal-Wallis test, followed by Dunn's post-test(23-24).

We applied the Spearman correlation coefficient to check the correlations between the quantitative variables and used the following classification: 0.1 to 0.29 (weak correlation), 0.30 to 0.49 (moderate correlation), and greater than or equal to 0.50 (strong correlation)(13). To study the associations between the qualitative variables, we applied the Pearson's chi-squared test and, for the cases in which the assumptions were not met, we used Fisher's exact test(23-24). For all analyses we used the statistical software SAS version 9.4 and SPSS version 24.0.

The project was approved by the Research Ethics Committee of the University of Campinas, no. 2,305.539 and all recommendations of Resolution 466/2012 referring to research with human beings were complied with. The manuscript followed the recommendations of the guide Revised Standards for Quality Improvement Reporting Excellence (SQUIRE 2.0)(25).

\section{Results}

Patients with MS under outpatient follow-up were predominantly female $(71.4 \%)$, with mean age of 40.2 years $(S D=11.7)$, born $(88.1 \%)$ and living $(96.4 \%)$ in the state of São Paulo, married (74.8\%), with complete secondary education $(28.6 \%)$ or complete higher education (27.4\%). They had mean family income of 3.9 minimum wages and lived with two persons at home. Regarding the professional status, $70.2 \%$ were inactive.

Clinically, relapsing-remitting MS (RRMS) predominated $(84.5 \%)$. The symptoms onset was on average 11.8 years prior $(S D=8.1)$, the diagnosis time was 9.1 years $(S D=6.8)$, and the mean EDSS score was 3.9 points $(S D=2.3)$. Regarding the clinical manifestations, we highlight the pyramidal (89.3\%), disorders of mental/ emotional functions (79.8\%), cerebellar alterations $(76.2 \%)$, report of fatigue $(69.0 \%)$, vesical disorders $(48.8 \%)$ and intestinal disorders (48.8\%). Regarding the medications in use, we found mainly Interferon (33.3\%) and Natalizumab (26.2\%).

Table 1 presents the results of the self-care and functioning evaluation scores.

We found that most patients were classified as "having self-care" (82.1\%); with moderate dependence (51.2\%) for BADLs; partial dependence for IADLs (55.9\%); and more active for AADLs (85.7\%) (Table 1). When evaluating the influence of functioning and sociodemographic measures on the ASA-R, we found no correlation between the variables (Table 2). By investigating in isolation the influence of clinical variables on patient self-care, we found that only the presence of pyramidal manifestations interfered with this measure $(p=0.0281)$.

Table 1 - Characterization of the self-care and functioning evaluation scores of patients with multiple sclerosis $(n=84)$. Campinas, SP, Brazil, 2017

\begin{tabular}{|c|c|c|c|c|}
\hline Variables & n (\%) & Mean (SD)* & Median & Variation \\
\hline Appraisal of Self-care Agency (ASA-R) ${ }^{\dagger}$ & & $53,8(3,9)$ & 53,5 & $45,0-65,0$ \\
\hline Having capacity for self-care & $69(82,1)$ & & & \\
\hline Developing capacity self-care & $15(17,9)$ & & & \\
\hline Classification for $\mathrm{B}^{\ddagger}$ & & $84,0(18,9)$ & 87,5 & $5,0-100,0$ \\
\hline Independent & $28(33,3)$ & & & \\
\hline Slight dependence & $8(9,5)$ & & & \\
\hline Moderate dependence & $43(51,2)$ & & & \\
\hline Severe dependence & $3(3,6)$ & & & \\
\hline Total dependence & $2(2,4)$ & & & \\
\hline Classification for LBS§ & & $18,4(3,6)$ & 20,0 & $8,0-21,0$ \\
\hline Independent & $37(44,0)$ & & & \\
\hline Partial dependence & $47(55,9)$ & & & \\
\hline Classification for AADL" & & $6,6(2,9)$ & 6,5 & $1,0-12,0$ \\
\hline More active & $72(85,7)$ & & & \\
\hline Less active & $12(14,3)$ & & & \\
\hline
\end{tabular}


Table 2 - Comparison of the sociodemographic and clinical variables with the self-care and functioning scores. Campinas, SP, Brazil, 2017

\begin{tabular}{|c|c|c|c|c|}
\hline Variables & ASA-R* & $\mathrm{BI}^{\dagger}$ & LBS $^{\ddagger}$ & AADL $\$$ \\
\hline \multicolumn{5}{|l|}{ Age } \\
\hline$\rho^{\|}$ & $-0,0787$ & $-0,4937$ & $-0,3929$ & $-0,4054$ \\
\hline p-value $\pi$ & 0,4770 & $<0,0001$ & 0,0002 & 0,0001 \\
\hline $\mathrm{N}$ & 84 & 84 & 84 & 84 \\
\hline \multicolumn{5}{|l|}{ Income } \\
\hline$\rho^{\|}$ & $-0,1738$ & 0,0489 & 0,2226 & 0,2371 \\
\hline p-value $\pi$ & 0,1208 & 0,6646 & 0,0458 & 0,0331 \\
\hline $\mathrm{N}$ & 81 & 81 & 81 & 81 \\
\hline \multicolumn{5}{|c|}{ Diagnosis time } \\
\hline$\rho^{\|}$ & $-0,0724$ & $-0,3282$ & $-0,2037$ & $-0,2609$ \\
\hline p-value $\pi$ & 0,5127 & 0,0023 & 0,0631 & 0,0165 \\
\hline $\mathrm{N}$ & 84 & 84 & 84 & 84 \\
\hline \multicolumn{5}{|c|}{ Symptoms onset time } \\
\hline$\rho^{\|}$ & $-0,1210$ & $-0,4794$ & $-0,2631$ & $-0,1879$ \\
\hline p-value $\pi$ & 0,2729 & $<0,0001$ & 0,0156 & 0,0869 \\
\hline $\mathrm{N}$ & 84 & 84 & 84 & 84 \\
\hline \multicolumn{5}{|c|}{ Outpatient follow-up time } \\
\hline$\rho^{\|}$ & $-0,0238$ & $-0,3692$ & $-0,2066$ & $-0,1583$ \\
\hline p-value $\pi$ & 0,8319 & 0,0006 & 0,0626 & 0,1554 \\
\hline $\mathrm{n}$ & 82 & 82 & 82 & 82 \\
\hline \multicolumn{5}{|c|}{ EDSS $^{* *}$ score } \\
\hline$\rho^{\|}$ & $-0,0388$ & $-0,7832$ & $-0,5728$ & $-0,5166$ \\
\hline p-value ${ }^{\pi}$ & 0,7262 & $<0,0001$ & $<0,0001$ & $<0,0001$ \\
\hline $\mathrm{n}$ & 84 & 84 & 84 & 84 \\
\hline
\end{tabular}

Through analysis of the correlations between numerical variables and functioning scales scores, we found that age and EDSS score showed negative correlation with all measures. In addition, the symptoms onset time, diagnosis time, and outpatient follow-up time variables also negatively influenced at least one of these measures (Table 2). The self-care scale score was not influenced by any numerical variable.

By examining the comparison measures, through analysis of the functioning and self-care measures categorized, we found that the younger people who had shorter diagnosis time or outpatient follow-up time were more functional. Patients with lower EDSS scores were more independent for BADLs, IADLs, and AADLs, and those with higher income were more active for AADLs (Table 3).

Table 4 shows that the higher the educational level, the greater the independence in relation to all activities of daily living. By applying Dunn's post-test, we observed that this difference was significant when comparing patients with elementary education and patients with complete higher education as to the three measures of functioning. In addition, patients with preserved functioning maintained an active professional status. While those with clinical manifestations of the disease presented greater dependence for all activities.

Table 3 - Comparison of the sociodemographic and clinical variables with the groups identified by the evaluation of functioning $(n=84)$. Campinas, SP, Brazil, 2017

\begin{tabular}{|c|c|c|c|c|c|c|}
\hline \multicolumn{2}{|c|}{ Variables } & \multirow[t]{2}{*}{$\mathbf{n}$} & \multirow[t]{2}{*}{ Mean (SD*) } & \multirow[t]{2}{*}{ Median } & \multirow[t]{2}{*}{ Variation } & \multirow[t]{2}{*}{ p-value ${ }^{\dagger}$} \\
\hline & $\mathrm{BI}^{\ddagger}$ & & & & & \\
\hline \multirow[t]{2}{*}{ Age } & Independent/Slight & 36 & $33,2(9,8)$ & 31,0 & $18,0-61,0$ & $<0,001$ \\
\hline & Moderate/Severe/Total & 48 & $45,5(10,2)$ & 46,5 & $26,0-66,0$ & \\
\hline \multirow[t]{2}{*}{ Diagnosis } & Independent/Slight & 36 & $6,7(5,5)$ & 5,0 & $0,0-20,0$ & 0,010 \\
\hline & $\begin{array}{l}\text { Moderate/ } \\
\text { Severe/Total }\end{array}$ & 48 & $10,8(7,2)$ & 9,5 & $0,3-26,0$ & \\
\hline \multirow[t]{2}{*}{ Symptoms onset } & Independent/Slight & 36 & $7,9(6,0)$ & 7,0 & $0,3-20,0$ & 0,001 \\
\hline & Moderate/Severe/Total & 48 & $14,8(8,3)$ & 16,0 & $1,0-33,0$ & \\
\hline \multirow[t]{2}{*}{ Outpatient follow-up } & Independent/Slight & 35 & $5,8(5,3)$ & 4,0 & $0,0-17,0$ & 0,005 \\
\hline & Moderate/Severe/Total & 47 & $10,4(7,4)$ & 9,0 & $0,0-26,0$ & \\
\hline \multirow[t]{3}{*}{ EDSS score $^{2}$} & Independent/Slight & 36 & $2,1(1,4)$ & 2,0 & $0,0-6,0$ & $<0,001$ \\
\hline & Moderate/Severe/Total & 48 & $5,4(1,7)$ & 6,0 & $2,0-8,0$ & \\
\hline & LBS" & & & & & \\
\hline \multirow[t]{2}{*}{ Age } & Independent & 37 & $36,2(9,2)$ & 34,0 & $23,0-57,0$ & 0,004 \\
\hline & Partially dependent & 47 & $43,4(12,6)$ & 45,0 & $18,0-66,0$ & \\
\hline \multirow[t]{2}{*}{ EDSS score } & Independent & 37 & $2,8(1,9)$ & 2,0 & $0,0-6,0$ & $<0,001$ \\
\hline & Partially dependent & 47 & $4,9(2,1)$ & 5,5 & $1,0-8,0$ & \\
\hline & AADL ${ }^{\dagger \dagger}$ & & & & & \\
\hline \multirow[t]{2}{*}{ Age } & More active & 72 & $38,8(10,9)$ & 37,0 & $18,0-62,0$ & 0,014 \\
\hline & Less active & 12 & $48,5(13,0)$ & 48,5 & $23,0-66,0$ & \\
\hline \multirow[t]{2}{*}{ Income } & More active & 69 & $3702,9(2500,5)$ & 3000,0 & $700,0-12000,0$ & 0,011 \\
\hline & Less active & 12 & $3658,3(6770,3)$ & 1550,0 & $600,0-25000,0$ & \\
\hline \multirow[t]{2}{*}{ Diagnosis } & More active & 72 & $8,4(6,6)$ & 7,0 & $0,0-26,0$ & 0,018 \\
\hline & Less active & 12 & $13,2(6,6)$ & 11,5 & $1,0-23,0$ & \\
\hline \multirow[t]{2}{*}{ EDSS§ score } & More active & 72 & $3,7(2,2)$ & 3,2 & $0,0-8,0$ & 0,020 \\
\hline & Less active & 12 & $5,4(2,1)$ & 6,0 & $1,5-7,5$ & \\
\hline
\end{tabular}

*SD = Standard Deviation; ${ }^{+} \mathrm{p}$-value = level of significance; ${ }^{\mathrm{B}} \mathrm{BI}=$ Barthel Index; ${ }^{EDSS}=$ Kurtzke Expanded Disability Status Scale; $"$ LBS = Lawton and Brody Scale; "AADL = Advanced Activities of Daily Living 
Table 4 - Comparison between the functioning scores and the sociodemographic and clinical variables of patients with multiple sclerosis $(n=84)$. Campinas, SP, Brazil, 2017

\begin{tabular}{|c|c|c|c|c|c|}
\hline Variables & $\mathrm{n}$ & Mean $\left(\mathrm{SD}^{*}\right)$ & Median & Variation & p-value ${ }^{\dagger}$ \\
\hline \multicolumn{6}{|l|}{$\mathbf{B I}^{\ddagger}$} \\
\hline \multicolumn{6}{|l|}{ Educational level } \\
\hline Elementary education & 21 & $75,5(20,8)$ & 80,0 & $25,0-100,0$ & \multirow{3}{*}{0,016} \\
\hline Secondary education & 29 & $85,7(14,7)$ & 90,0 & $45,0-100,0$ & \\
\hline Higher education & 34 & $87,9(19,8)$ & 95,0 & $5,0-100,0$ & \\
\hline \multicolumn{6}{|l|}{ Professional status } \\
\hline Active & 25 & $90,8(16,4)$ & 100,0 & $45,0-100,0$ & \multirow{2}{*}{0,003} \\
\hline Inactive & 59 & $81,2(19,4)$ & 85,00 & $5,0-100,0$ & \\
\hline \multicolumn{6}{|l|}{ Cerebellar manifestation } \\
\hline Present & 64 & $81,1(19,5)$ & 85,0 & $5,0-100,0$ & \multirow{2}{*}{0,001} \\
\hline Absent & 20 & $93,5(13,5)$ & 100,0 & $50,0-100,0$ & \\
\hline \multicolumn{6}{|c|}{ Vesical/intestinal manifestation } \\
\hline Present & 41 & $75,8(21,2)$ & 80,0 & $5,0-100,0$ & \multirow{2}{*}{$<0,001$} \\
\hline Absent & 43 & $91,9(12,4)$ & 100,0 & $50,0-100,0$ & \\
\hline \multicolumn{6}{|l|}{ LBS $\$$} \\
\hline \multicolumn{6}{|l|}{ Educational level } \\
\hline Elementary education & 21 & $16,4(4,9)$ & 19,0 & $8,0-21,0$ & \multirow{3}{*}{0,045} \\
\hline Secondary education & 29 & $18,9(2,6)$ & 20,0 & $12,0-21,0$ & \\
\hline Higher education & 34 & $19,3(3,1)$ & 21,0 & $8,0-21,0$ & \\
\hline \multicolumn{6}{|l|}{ Professional status } \\
\hline Active & 25 & $19,9(2,3)$ & 21,0 & $11,0-21,0$ & \multirow{2}{*}{0,007} \\
\hline Inactive & 59 & $17,8(3,9)$ & 19,0 & $8,0-21,0$ & \\
\hline \multicolumn{6}{|l|}{ Cerebellar manifestation } \\
\hline Present & 64 & $17,8(3,8)$ & 19,0 & $8,0-21,0$ & \multirow{2}{*}{0,001} \\
\hline Absent & 20 & $20,2(2,3)$ & 21,0 & $11,0-21,0$ & \\
\hline \multicolumn{6}{|c|}{ Vesical/intestinal manifestation } \\
\hline Present & 41 & $17,5(3,9)$ & 19,0 & $8,0-21,0$ & \multirow{2}{*}{0,003} \\
\hline Absent & 43 & $19,3(3,1)$ & 21,0 & $8,0-21,0$ & \\
\hline \multicolumn{6}{|l|}{ AADL" } \\
\hline \multicolumn{6}{|l|}{ Educational level } \\
\hline Elementary education & 21 & $4,9(2,9)$ & 5,0 & $1,0-10,0$ & \multirow{3}{*}{0,008} \\
\hline Secondary education & 29 & $6,9(2,4)$ & 7,0 & $2,0-10,0$ & \\
\hline Higher education & 34 & $7,5(2,9)$ & 8,0 & $2,0-12,0$ & \\
\hline \multicolumn{6}{|l|}{ Professional status } \\
\hline Active & 25 & $8,2(2,5)$ & 9,0 & $3,0-12,0$ & \multirow{2}{*}{0,001} \\
\hline Inactive & 59 & $5,9(2,8)$ & 6,0 & $1,0-12,0$ & \\
\hline \multicolumn{6}{|l|}{ Cerebellar manifestation } \\
\hline Present & 64 & $6,2(2,9)$ & 6,0 & $1,0-12,0$ & \multirow{2}{*}{0,020} \\
\hline Absent & 20 & $7,9(2,5)$ & 8,5 & $2,0-11,0$ & \\
\hline
\end{tabular}

\section{Discussion}

Our results showed the implications of MS on selfcare and on the basic, instrumental, and advanced activities of daily living of patients. Such evidence corroborates previous studies that sought to explore the changes in the disabilities according to the severity of the disease(26-28). The manifestations of MS are highly variable and often unpredictable, with its course evolving from mild and infrequent relapses, with limited impact on functional capacity, to rapidly accumulating disability, loss of independent ambulation, and extensive cognitive impairment ${ }^{(29)}$.

Regarding the profile of our patients, there was predominance of females and with mean age of 40.2 years and with high educational level, in line with 
national studies(30-31) and international studies ${ }^{(27)}$. We highlight that the age of our group ranged from 18 years to 66 years. We found in the literature that most patients are diagnosed at the beginning of adulthood, between 20 and 40 years of age, that the disease is twice as prevalent among women, and that higher educational level is protective against the cognitive function decline and disease overload ${ }^{(32-33)}$. This demonstrates that MS causes neurological disability in young adults ${ }^{(30)}$, leading to serious adverse effects on the daily living of many patients, including the loss of capacity for work ${ }^{(29)}$.

However, it is worth adding that some studies have pointed out that women, individuals with higher education, and youth with MS have greater selfmanagement of the disease ${ }^{(34-35)}$. This term is defined as an active process of dealing with the disease through adherence to treatment, participation in therapeutic decision-making, active search for information about the disease and new treatment options, maintenance of social relationships and emotional balance, that is, it incorporates self-monitoring and symptom management. Therefore, self-management is part of self-care in order to facilitate better adaptation to the disease, reduce the likelihood of secondary complications, contribute to quality of life, reduce disability, and improve outcomes with treatment ${ }^{(34,36)}$.

As the treatment schemes for MS can be complex, patients with low levels of literacy may have greater difficulty to understand and complying with the treatment. This may pose a challenge to care and lead to self-care impairment and cause functional disability, as we observed.

Contributing to the characterization of this public, we found that most of the patients were inactive and that the family income was $\mathbf{3 . 9}$ minimum salaries, today approximately BRL $3,720^{(29)}$. In addition, we found that patients with higher income were more active for AADLs and those with preserved functioning maintained an active professional status.

A study conducted in Sweden, which compared salaries between the general population and patients with MS before and after the diagnosis of the disease, found that the gross salary was similar before, but shortly after the diagnosis of the disease it diminished. After eleven years of follow-up, people without disease had an increase of 7,520 euros in their salaries, while patients with MS had a loss of 9,010 euros, which represents more than $30 \%$ of the mean annual gross salary in Sweden(29). Moreover, since the initial symptoms of MS appear during the economically active age of a person, this may impact the ability to maintain a job; however, rates for unemployment and retirement due to disability vary between countries ${ }^{(37-39)}$.
The literature shows that the treatment of MS is costly, which makes many people unable to afford it, delaying or preventing the search for medical treatment ${ }^{(27)}$. Often, patients cannot afford the medical care expenses and because of that do not attend the consultations or do not undergo the diagnostic exams or, even, omits their symptoms in an effort to reduce costs(27). This may have caused the inconsistency between the symptoms onset time (11.8 years) and the diagnosis time (9.1 years). It is worth noting that the time between the clinical onset of MS and the diagnosis is the most important predictor of the severity of disability ${ }^{(40)}$.

The clinical manifestations that predominated in this study were the pyramidal (paresis and paresthesia), cerebellar (ataxia and dysarthria) and vesical-intestinal ones. They are often originated after an outbreak of the disease and progress from a transient symptom to a sequela. However, many patients feel discouraged as to seeking traditional care, in which there is a delay in scheduling and, consequently, in feedback(27).

In addition, there is the fact that we work with individuals of the $Y$ and $Z$ generations, born in the Digital age, in which communication is practically instantaneous. In this context, they increasingly seek for clinics with more affordable prices, emergency room, or search for information on the Internet. Such practices may result in a delay in the diagnosis and correct treatment. It should be emphasized the importance of effective care, due to the complexity of the disease, as well as its chronic nature(27).

It is found in the literature that the aging process leads to cerebral trophic decrease, which contributes to the neurodegeneration process and decreases remyelination. The compact myelination of the cerebral white matter ends at 40 years of age and begins to degenerate in the following years. Therefore, the more limited recovery after the clinical outbreaks of the disease, in the first five years, can cause progression of MS and lead to sequelae, loss of self-care, and decreased functioning(41). Moreover, the decline in functional reserve produces the insidious accumulation of physical and cognitive disability, which characterizes what is traditionally considered as the progressive phase of the disease ${ }^{(4)}$.

Thus, patients with greater clinical compromise and with longer symptoms onset time and/or diagnosis time showed higher levels of dependence. This result is evidenced in another study conducted in the city of Ankara, Turkey, in which the researchers confirmed that, in the first 10 years of the disease, patients tend to be slightly more dependent to perform the activities of daily living and with a greater need for self-care ${ }^{(27)}$. 
It should be noted that, in the present study, most patients with MS were classified as "having capacity for self-care" and presented higher dependence to perform the basic activities, mainly for sphincter control, when compared with the instrumental or advanced activities of daily living. As for self-care, only the presence of pyramidal sequelae interfered with this measure.

The clinical course of multiple sclerosis is difficult to be predicted in the different groups and individuals. A study that discusses the topographic models of MS, as a new approach to characterize the clinical course of the disease, reports that the location of the lesion defines the clinical symptoms and the functional systems affected: those on the spinal cord produce pyramidal, sensory, intestinal, and bladder symptoms; those on the brain stem and cerebellum cause diplopia, vertigo, ataxia and imbalance; and those on the hemispheres produce brain signals, most notably cognitive dysfunction. In light of that, they reported that spinal cord lesions, in particular, have shown worse prognosis and loss of functional reserve, which will limit their self-care in advance ${ }^{(4)}$.

This reinforces the idea that biopsychosocial mechanisms are associated with the level of disability. Since MS is a neurodegenerative disease, it affects neural structures, which hinders or even prevents the transmission of stimuli to the other systems and organs of the body, and this has direct impact on cognition, sphincter control, manual skills, mobility, transfer, and is evident in difficulties to perform the basic and instrumental activities of daily living(26,42). These factors should be considered in the survey of nursing diagnoses performed by nurses ${ }^{(30,43)}$.

A study aimed at implementing the Systematization of Nursing Care for outpatient follow-up of patients with MS found as the most frequent nursing diagnoses, according to NANDA International, Inc. (NANDA-I), impaired physical mobility (00085), sleep pattern disorders (00198), self-care deficits, activity intolerance (00092), impaired urinary elimination (00016), risk for ineffective personal coping (00069), constipation (00011), impaired memory (00131), sexual dysfunction (00059), ineffective control of therapeutic regimen (00080), and acute pain $(00132)^{(10)}$.

Often times, after the onset of demyelinating diseases, psychiatric disorders may arise ${ }^{(8)}$. From this perspective, the maintenance of AADLs, related to social interaction, are beneficial to these patients, because they generate benefits for both physical and psychological health. In addition to improving self-esteem, decreasing social isolation and the onset of depressive disorders( ${ }^{(30)}$.

Some studies have also pointed out the protective effect of AADLs by decreasing cognitive declines and the onset of dementia, avoiding the decline of memory and language, executive functions, attention, and global cognitive functions ${ }^{(8,44)}$. Therefore, nurses should act since the onset of the first clinical manifestations, by providing emotional support to the person, who will possibly be shaken, due to the possible disabilities and the changes that will occur not only in the body, but also in the lifestyle ${ }^{(8,26)}$. This may be conducted through motivation to preserve self-care activities, as well as through support and suggestion of alternatives for the functional disabilities ${ }^{(10,30)}$.

The planning of care, as well as its implementation must be consistent with the needs observed, considering, mainly, the time of manifestation of the disease, since we know that it has a crucial role for functional decline. A beneficial factor is the inclusion of family members in this care plan, which will positively contribute to the promotion and rehabilitation of this patient. This factor may contribute directly by fostering greater willingness to perform all activities of daily living, by stimulating the sociability and the functioning of the individuals ${ }^{(45)}$.

In this context, health professionals should always be attentive to care management, since the deprivation of these activities has a negative effect for these individuals, constituting a possible predictor of social isolation and loss of functioning. Thus, the interaction with the family and society are of fundamental importance to contribute to the promotion and rehabilitation of the patient's health.

Moreover, the evaluation of the multidisciplinary team is mandatory, since there are countless clinical, functional and self-care demands. In this context, it is important that nurses get involved in a broader way in the promotion and rehabilitation of these patients' health, working not only in the implementation and systematization of care, but also by stimulating the development of self-care, functioning and sociability. So that the perspective in relation to the individual reaches far beyond the outpatient or bedside scope, with the development of new researches and more and better professional training for these demands that accompany patients with chronic-degenerative diseases.

We highlight some limitations of the present study as to not finding people classified as having greater need for self-care, in addition to the study design, which, for being cross-sectional, does not enable the establishment of cause and effect relation. Other limitations associated with the use of secondary data, such as the possibility of reporting errors, should also be considered. Furthermore, we emphasize the low number of studies on self-care assessment or that study the functioning of people with MS, which made it difficult to compare the results with other findings. 


\section{Conclusion}

The results of this study evidenced that the selfcare levels of the patients with MS were preserved and $82.1 \%$ were classified as "having capacity for self-care." They presented more pronounced functional limitation in BADLs, if compared with IADLs, $55.9 \%$ had partial dependence for IADLs and 51.2\%, had moderate dependence for BADLs. As for AADLs, $85.7 \%$ were more active. In addition, disease duration was strongly correlated with greater number of disabilities and the best socioeconomic and educational profiles proved to be protective factors for functionality.

This was one of the first studies in Nursing that verified the relation between self-care and functionality of patients with MS, using validated scales and a multidimensional evaluation. We hope that these findings stimulate new researches in the area of rehabilitation in nursing, aiming at the implementation of interventions geared toward the actual needs of the individuals.

\section{Acknowledgement}

We would like to thank all employees of the Neurology Outpatient Clinic of the Clinics Hospital at Unicamp, mainly the nurse Gislaine Aparecida Alves Kikuta by support for the research.

\section{References}

1. Cotsapas C, Mitrovic M, Hafler D. Multiple sclerosis. Handb Clin Neurol. 2018;148:723-30. doi: 10.1016/ B978-0-444-64076-5.00046-6.

2. GBD 2015 Neurological Disorders Collaborator Group. Global, regional, and national burden of neurological disorders during 1990-2015: a systematic analysis for the Global Burden of Disease Study 2015. Lancet Neurol. 2017 Nov;16(11):877-97. doi: 10.1016/S14744422(17):30299-5.

3. Brownlee WJ, Hardy TA, Fazekas F, Miller DH. Diagnosis of multiple sclerosis: progress and challenges. Lancet. 2017 Apr 1;389(10076):1336-46. doi: 10.1016/ S0140-6736(16)30959-X.

4. Krieger SC, Sumowski J. New Insights into Multiple Sclerosis Clinical Course from the Topographical Model and Functional Reserve. Neurol Clin. 2018 Feb;36(1):13-25. doi: 10.1016/j.ncl.2017.08.003.

5. Novais PGN, Batista KM, Grazziano ES, Amorim MHC. The effects of progressive muscular relaxation as a nursing procedure used for those who suffer from stress due to multiple sclerosis. Rev. Latino-Am. Enfermagem. 2016 Sep 1; 24:e2789. doi: 10.1590/1518-8345.1257.2789
6. Damasceno A, Damasceno BP, Cendes F. Subclinical MRI disease activity influences cognitive performance in MS patients. Mult Scler Relat Disord. 2015 Mar;4(2):137-43. doi: 10.1016/j.msard.2015.01.006

7. Reich DS, Lucchinetti CF, Calabresi PA. Multiple Sclerosis. N Engl J Med. 2018 Jan 11;378(2):169-80. doi: $10.1056 /$ NEJMra1401483

8. Crabtree-Hartman E. Advanced Symptom Management in Multiple Sclerosis. Neurol Clin. 2018 Feb;36(1)197-218. doi:10.1016/j.ncl.2017.08.015.

9. Kraft $\mathrm{GH}$, Johnson $\mathrm{KL}$, Amtmann $\mathrm{D}$, Bamer $\mathrm{AM}$, Bombardier $\mathrm{CH}$, Ehde $\mathrm{DM}$, et al. Future Directions of Multiple Sclerosis Rehabilitation Research. Phys Med Rehabil Clin N Am. 2013 Nov;24(4)721-30. doi: 10.1016/j.pmr.2013.06.005.

10. Corso NAA, Gondim APS, D'Almeida PCR, Albuquerque MGF. Nursing care systematization for outpatient treatment care of patients with multiple sclerosis. Rev Esc Enferm USP. [Internet] 2013 Jun [cited Aug 20, 2018];47(3):750-5. Available from: http://www. scielo.br/scielo.php?script=sci_arttext\&pid=S008062342013000300750\&lng=en. http://dx.doi.org/10.1590/ S0080-623420130000300032.

11. World Health Organization Regional Office for South-East Asia. Self care for health: a handbook for community health workers \& volunteers. WHO Library Cataloguing-in-Publication data. [Internet] 2013 [cited Aug 20, 2018];1-160. Available from: http://apps. searo.who.int/PDS_DOCS/B5084.pdf.

12. World Health Organization. How to use the ICF: A practical manual for using the International Classification of Functioning, Disability and Health (ICF). Exposure draft for comment [Internet]. Geneva: WHO 2013 Oct [cited Aug 20, 2018]. Available from: http://www.who. int/classifications/drafticfpracticalmanual.pdf

13. Cohen J. Statistical power analysis for the behavioral sciences. 2.ed. New Jersey: Lawrence Erlbaum Associates; 1988. 559 p.

14. Damásio BF, Koller SH. The Appraisal of SelfCare Agency Scale - Revised (ASAS-R): adaptation and construct validity in the Brazilian contexto. Cad Saúde Pública. [Internet] 2013 Out [cited Aug 20, 2018]; 29(10):2071-82. Available from: http://www. scielo.br/scielo.php?script=sci_arttext\&pid=S0102$311 \times 2013001000023 \&$ lng=en.http://dx.doi.org/10.1590/ 0102-311X00165312.

15. Stacciarini TS, Pace AE. Translation, adaptation and validation of a self-care scale for type 2 diabetes patients using insulin. Acta Paul Enferm. [Internet] 2014 Jun [Cited Aug 20, 2018];27(3):221-9. Available from: http://www.scielo.br/scielo.php?script= sci_arttext\&pid=S0103-21002014000300221\&lng=en. http://dx.doi.org/10.1590/1982-0194201400038. 
16. Santos RL, Virtuoso JS Júnior. Reliability of the Brazilian version of the Scale of Instrumental Activities of Daily Living. RBPS. 2008 Nov 16;21(4): 290-6. doi: 10.5020/575

17. Minosso JSM, Amendola F, Alvarenga MRM, Oliveira MAC. Validation of the Barthel Index in elderly patients attended in outpatient clinics, in Brazil. Acta Paul Enferm. [Internet] 2010 Apr [cited Aug 20, 2018];23(2): 218-23. Available from: http://www.scielo.br/scielo.php?script=sci_arttext\& pid=S0103-21002010000200011\&lng=en. http://dx.doi. org/10.1590/S0103-21002010000200011.

18. Dias EG, Andrade FB, Duarte YAO, Santos JLF, Lebrão ML. Advanced activities of daily living and incidence of cognitive decline in the elderly: the SABE Study. Cad Saúde Pública. [Internet] 2015 Aug [cited Aug 20, 2018];31(8): 1623-35. Available from: http:// www.scielo.br/scielo.php?script=sci_arttext\&pid=S0102311X2015000801623\&lng=en.http://dx.doi.org/10.1590/ 0102-311X00125014.

19. Kurtzke JF. Rating neurologic impairment in multiple sclerosis: an expanded disability status scale (EDSS). Neurology. [Internet] 1983 Nov [cited Sep13, 2017];33:1444-52. Available from: https://www.ncbi. nlm.nih.gov/pubmed/6685237

20. Coura AS, Enders BC, França ISX, Vieira CENK, Dantas DNAD, Menezes DJCM. Ability for self-care and its association with sociodemographic factors of people with spinal cord injury. Rev Esc Enferm USP. [Internet] 2013 [citedAug 20,2018];47(5):1154-62. Availablefrom: http:// www.scielo.br/scielo.php?script=sci_arttext\&pid=S008062342013000501150\&lng=en. http://dx.doi.org/10.1590/ S0080-623420130000500020.

21. Dias EG, Duarte YAO, Almeida MHM, Lebrão ML. The advanced activities of daily living at component of the functional assessment in elderly people. Rev Ter Ocup Univ São Paulo. [Internet] 2014 Nov [cited Aug 20, 2018];25(3): 225-32. Available from: http://www.revistas.usp.br/rto/article/view/75910/ pdf_66 Doi: 10.11606/issn.2238-6149.v25i3p225-232. 22. Azeredo Z, Matos E. Grau de Dependência em Doentes que sofreram AVC. RFML. [Internet] 2003 Aug [cited Ago 20, 2018];8(4):199-204. Available from: https://scholar.google.com/scholar_lookup?title=Grau+ de+depend\%C3\%AAncia+em+doentes+que+sofreram + AVC\&author $=$ Azeredo + Z\&author $=$ Matos + E\&publicati on_year $=2003 \&$ journal $=$ Rev + Fac+Med +Lisboa\&volume $=8 \&$ issue $=4$ \&pages $=199-204$

23. Barkan H. Statistics in clinical research: Important considerations. Ann Card Anaesth. 2015 Mar; 18(1):74-82. doi: 10.4103/0971-9784.148325

24. Lash TL, Fox MP, MacLehose RF, Maldonado G, McCandless LC, Greenland S. Good practices for quantitative bias analysis. Int J Epidemiol. 2014; 43(6):1969-85. doi: 10.1093/ije/dyu149

25. Goodman D, Ogrinc G, Davies L, Baker GR, Barnsteiner J, Foster TC, et al. Explanation and elaboration of the SQUIRE (Standards for Quality Improvement Reporting Excellence) Guidelines, V.2.0: examples of SQUIRE elements in the healthcare improvement literature. BMJ Qual Saf. 2016 Dec; 25(12):e7. doi: 10.1136/bmjqs-2015-004480

26. Conradsson D, Ytterberg C, von Koch L, Johansson S. Changes in disability in people with multiple sclerosis: a 10-year prospective study. J Neurol. 2018;265:119-126. doi: 10.1007/s00415-017-8676-8.

27. Basak T, Unver V, Demirkaya S. Activities of Daily Living and Self-Care Agency. Reha-bil Nurs. 2015;40(1):60-5. doi: 10.1002/rnj.153.

28. Chruzander C, Johansson S, Gottberg K, Einarsson U, Fredrikson S, Holmqvist LW, et al. A 10-year follow-up of a population-based study of people with multiple sclerosis in Stockholm, Sweden: changes in disability and the value of diferente factors in predicting disability and mortality. J Neurol Sci. 2013;332(1-2):121-127. doi: $10.1016 /$ j.jns.2013.07.003

29. Landfeldt E, Castelo-Branco A, Svedbom A, Löfroth E, Kavaliunas A, Hillert J. Personal Income Before and After Diagnosis of Multiple Sclerosis. Value in Health. 2018; 21:590-95. doi: 10.1016/j.jval.2017.09.021.

30. Damasceno A, Von Glehn F, Brandão CO, Damasceno BP, Cendes F. Prognostic indicators for long-term disability in multiple sclerosis patients. J Neurol Sci. 2013;324(1-2):29-33. doi: 10.1016/j.jns.2012.09.020.

31. Costa TMS, Souza Neto VL, Domingos MMC, Silva BCO, Rodrigues IDCV, Silva RAR. A profile of nursing diagnoses in patients with multiple sclerosis: a cross-sectional study. Online Braz J Nurs. 2016;15(3): 433-42. doi: 10.17665/1676-4285.20165383

32. Rocca MA, Riccitelli GC, Meani A, Pagani E, Del Sette $P$, Martinelli $V$, et al. Cognitive reserve, cognition, and regional brain damage in MS: a 2-year longitudinal study. Mult Scler. 2018; 25(3):372-81. doi: 10.1177/1352458517750767.

33. Sumowski JF, Leavitt VM. Cognitive reserve in multiple sclerosis. Mult Scler. 2013;19(9): 1122-7. doi: $10.1177 / 1352458513498834$.

34. Wilski M, Tasiemski T. Illness perception, treatment beliefs, self-esteem, and self-efficacy as correlates of self-management in multiple sclerosis. Acta Neurol Scand. 2016; 133(5):338-45. doi: 10.1111/ane.12465. 35. Goodworth MCR, Stepleman L, Hibbard J, Johns L, Wright D, Hughes MD, et al. Variables associated with patient activation in persons with multiple Sclerosis. J Health Psychol. 2016; 21(1):82-92. doi: $10.1177 / 1359105314522085$. 
36. Galvão MTRLS, Janeiro JMSV. Self-care in nursing: self-management, self-monitoring, and the management of symptoms as related concepts. REME Rev Min Enferm. 2013;17(1):231-5. doi: 10.5935/1415-2762.20130019. 37. Miller A, DishonS. Health-related quality of life in multiple sclerosis: the impact of disability, gender and employment status. Qual Life Res. 2006;15(2):259-71. doi: 10.1007/s11136-005-0891-6.

38. Kobelt G, Thompson A, Berg J, Gannedahl M, Eriksson J. Newinsightsintotheburdenand costs of multiple sclerosis in Europe. Mult Scler. 2017;23(8):1123-36. doi: $10.1177 / 1352458517694432$.

39. Martínez-Ginés ML, García-Domínguez JM, ForeroL, Canal N, Rebollo P, Prefasi D, et al. Spanish validation of a specific measure to assess work-related problems in people with multiple sclerosis: The Multiple Sclerosis Work Difficulties Questionnaire (MSWDQ-23). Mult Scler Relat Disord. 2018;22:115-9. doi: 10.1016/j. msard.2018.04.003.

40. Signori A, Izquierdo G, Lugaresi A, Hupperts R, Grand'Maison $F$, Sola $P$, et al. Long-term disability trajectories in primary progressive MS patients: A latent class growth analysis. Mult Scler. 2018; 24(5):642-52. doi: $10.1177 / 1352458517703800$.

41. Hansen MR, Okuda DT. Multiple Sclerosis in the Contemporary Age: Understanding the Millennial Patient with Multiple Sclerosis to Create Next-Generation Care. Neurol Clin. 2018; 36(1):219-30. doi: 10.1016/j.ncl.2017.08.012.

42. Einarsson U, Gottberg K, FredriksonS, von Koch L, Widen Holmqvist $\mathrm{L}$. Activities of daily living and social activities in people with multiple sclerosis in Stockholm County. Clin Rehabil. 2006;20(6):543-51. doi: 10.1191/0269215506cr953oa.

43. Zeydan B, Kantarci OH. Progressive Forms of Multiple Sclerosis: Distinct Entity or Age-Dependent Phenomena. Neurol Clin. 2018; 36(1):163-71. doi: 10.1016/j.ncl.2017.08.006.

44. Patel VP, Walker LA, Feinstein A. Revisiting cognitive reserve and cognition in multiple sclerosis: A closer look at depression. Mult Scler. 2018;24(2):186-95. doi: 10.1177/1352458517692887.

45. Sposito G, Neri AL, Yassuda MS. Advanced activities of daily living (AADLs) and cognitive performance in community-dwelling elderly persons: Data from the
FIBRA Study - UNICAMP. Rev Bras Geriatr Gerontol. [Internet] 2016 [cited Aug 20, 2018];19(1):7-20. Available from: http://www.scielo.br/scielo.php?script=sci_ arttext\&pid=S1809-98232016000100007\&Ing=en. http:// dx.doi.org/10.1590/1809-9823.2016.15044.
Copyright $\odot 2019$ Revista Latino-Americana de Enfermagem This is an Open Access article distributed under the terms of the Creative Commons (CC BY).

This license lets others distribute, remix, tweak, and build upon your work, even commercially, as long as they credit you for the original creation. This is the most accommodating of licenses offered. Recommended for maximum dissemination and use of licensed materials. 